\title{
Shape-stabilized Phase Change Composite by Impregnation of Octadecane into Mesoporous $\mathrm{SiO}_{2}$
}

\section{Authors}

Takahiro Nomura*, Chunyu Zhu, Nan Sheng, Kazuki Tabuchi, Akihito Sagara, Tomohiro Akiyama

\section{Affiliation}

Center for Advanced Research of Energy and Materials, Hokkaido University, Kita 13, Nishi 8, Kita-ku, Sapporo 060-8628, Japan

*Corresponding author.

Tel.: +81 11706 6842; fax: +81 117066849

E-mail address: nms-tropy@eng.hokudai.ac.jp 


\begin{abstract}
We developed shape-stabilized phase change composites (PCCs) for building materials with high heat-storage density by vacuum impregnation of the phase change material (PCM) octadecane into mesoporous $\mathrm{SiO}_{2}$. We examined the effects of the average pore size of mesoporous $\mathrm{SiO}_{2}$ on the melting point and latent heat of the PCCs. Cyclic tests of melting and freezing were performed to evaluate leakage and degradation of the PCCs. The thermophysical properties of the PCCs were measured by differential scanning calorimetry, and the following results were obtained: 1) The impregnation ratio of the composites was above 0.95 ; therefore, almost all pores were completely filled with PCM. 2) The melting point of the PCMs decreased with decreasing average pore diameter, and the melting point was established as a function of average pore diameter from the Gibbs-Thomson equation, taking into account the existence of a nonfreezing layer on the surface of the pore wall. 3) The octadecane/mesoporous $\mathrm{SiO}_{2}$ composites retained the full amount of impregnated PCM, even after cyclic heating and cooling.
\end{abstract}

\title{
Keywords
}

Thermal energy storage; phase change material; latent heat; mesoporous material; building material 


\section{Nomenclature}

\begin{tabular}{|c|c|c|}
\hline$D_{P}$ & Pore diameter & $(\mathrm{nm})$ \\
\hline$h$ & Height of cylindrical pore & $(\mathrm{nm})$ \\
\hline$L$ & Specific latent heat & $\left(\mathrm{J} \mathrm{g}^{-1}\right)$ \\
\hline \multirow[t]{2}{*}{$L_{b u l k}$} & \multicolumn{2}{|c|}{ Latent heat of the bulk calculated on the basis of the } \\
\hline & amount of PCM in the pores & $\left(\mathrm{J} \mathrm{g}^{-1}\right)$ \\
\hline$L_{\mathrm{m}}$ & Molar latent heat & $\left(\mathrm{J} \mathrm{mol}^{-1}\right)$ \\
\hline$L_{\text {pore }}$ & Latent heat of PCM in the pores & $\left(J \cdot g^{-1}\right)$ \\
\hline$K_{G T}$ & Gibbs-Thomson constant & $(\mathrm{K} \cdot \mathrm{nm})$ \\
\hline$r$ & Pore radius & $(\mathrm{nm})$ \\
\hline$r_{e f}$ & Effective pore radius & $(\mathrm{nm})$ \\
\hline$T$ & Temperature & $(\mathrm{K})$ \\
\hline$T_{m, b u l k}$ & Melting point of bulk PCM & $(\mathrm{K})$ \\
\hline$T_{m}$ & Melting point & $(\mathrm{K})$ \\
\hline$T_{m, \text { pore }}$ & Melting point of PCM in pore & $(\mathrm{K})$ \\
\hline$V$ & Total volume of a pore & $\left(m^{3}\right)$ \\
\hline$V_{P}$ & Average pore volume & $\left(m^{3} g^{-1}\right)$ \\
\hline$v$ & Molar volume of liquid PCM & $\left(\mathrm{m}^{3} \mathrm{~mol}^{-1}\right)$ \\
\hline$W_{P C M}$ & Weight of PCM & (g) \\
\hline$W_{\text {Porous }}$ & Weight of porous material & (g) \\
\hline$\beta$ & Thickness of nonfreezing liquid layer & $(\mathrm{nm})$ \\
\hline$\gamma_{w s}$ & Wall-solid excess free energy & $\left(\mathrm{J} \mathrm{m}^{-2}\right)$ \\
\hline$\gamma_{w l}$ & Wall-liquid excess free energy & $\left(\mathrm{J} \mathrm{m}^{-2}\right)$ \\
\hline$\eta$ & Impregnation ratio & $(-)$ \\
\hline
\end{tabular}




\section{Introduction}

The increase in energy consumption and $\mathrm{CO}_{2}$ emission in the building sector is a serious issue. According to a recent report [1], the energy consumption of the building sector represents approximately $40 \%$ of the global energy consumption. The most feasible solutions to overcome this problem are electric and thermal energy-load levering by utilizing night-time power and solar heat. To implement these technologies, thermal energy storage (TES) that can store thermal energy for later use [2] is critical because of a mismatch in time between energy supply and demand. Under these circumstances, latent heat storage (LHS) for building systems has attracted significant attention. LHS is based on the storage or release of latent heat during a solid-liquid or solid-solid phase transition of a phase change material (PCM), which offers three main advantages, i.e., latent heat has higher heat capacity as compared to sensible heat storage, the PCM can be used as a heat source at a constant phase-transition temperature, and the reversible phase-changing process allows repeated use. In addition, there are many PCMs that are suitable for building systems, such as paraffin [3], hydrated salt [4, 5], fatty acids [6, 7], and sugar alcohols [8]. Based on these advantages, LHS is a promising technology for overcoming the mismatch in time between energy supply and demand. Many reports on building systems using PCMs have been published, and recent advances are summarized in several review papers [9-15]. In addition, 
specialized experimental and analytical technologies for PCMs have been developed [16, 17]. These technologies can further the application of PCMs in building materials by accelerating their practical implementation from lab-scale experiments.

In particular, phase change composite (PCC), which are PCM impregnated into porous materials, are promising because many building materials are composed of porous materials. Various naturally porous materials, such as expanded vermiculite [18, 19], expanded perlite [18, 20], diatomite [18, 21-23], bentonite clay [24], kaolin [25], and sand [24], have been reported as supporting materials for PCMs. These PCCs are applied to passive building systems, such as wallboards [15].

The pore diameter of a porous material is the most important parameter for the production of PCCs by impregnation. The main problem of PCCs prepared by impregnation is leakage of the PCM during melting. Amaia et al. reported that conventional porous materials present serious PCM leakage caused by exudation from macropores [26]. Considering the balance of forces at the pore surface, the advantage of using a porous material with smaller pores is that leakage can be avoided because of the stronger capillary force generated on a pore with a smaller diameter [27]. Recently, it was clarified that the thermophysical properties of a material inserted into mesopores drastically change as compared to those of bulk materials. It is well known that the 
melting point of water changes upon adsorption into nanopores, and this phenomenon has been applied to measure pore-size distributions [28-31]. Kanda et al. proposed the application of this phenomenon to LHS, in which the melting point of the PCM can be controlled by its incorporation into nanosized pores [32]. We reported that the change in the melting point of mannitol used as a sugar-alcohol PCM in mesopores with average diameters of $10 \mathrm{~nm}$ decreased by $10 \mathrm{~K}$, which led to enhanced thermal durability [33]. In light of the above discussion, the performance reliability of PCC should be investigated from the viewpoint of thermal durability—no leakage of PCM occurs after cyclic use - and accurate estimation of changes in the thermophysical properties of the PCM incorporated into a mesoporous material. In particular, applications of building material are keenly sensitive to temperature changes because the usual thermal comfort zone of buildings is in a narrow range between 293 and $303 \mathrm{~K}$ [15]. In addition, various porous materials having mesopores may change the thermophysical properties of the PCM inside the pore. However, only a few studies refer to the nanoconfinement effect on PCMs for building materials.

Therefore, the purposes of this study were to develop PCCs without any leakage and to analyse the thermophysical properties of PCM inside mesopores. Considering the application of PCCs in building materials, we used octadecane $\left(T_{m}=\right.$ 
$303 \mathrm{~K}$ ) as the $\mathrm{PCM}$ and porous $\mathrm{SiO}_{2}$ grains with different pore diameters in the range of approximately $10-50 \mathrm{~nm}$ as the mesoporous matrix. 


\section{Experiment}

\section{1 Materials}

Octadecane $\left(\mathrm{C}_{12} \mathrm{H}_{30}\right.$, melting point: $T_{m}=303 \mathrm{~K}$, latent heat: $\left.L_{\text {bulk }}=223 \mathrm{~J} \mathrm{~g}^{-1}\right)$ was selected as the PCM for application in building materials.

Table 1 lists the specifications of the mesoporous $\mathrm{SiO}_{2}$ grains that were used to support the PCM in the pores. $\mathrm{SiO}_{2}$ grains prepared by a sol-gel process were obtained from Fuji Silysia Chemical Co., LTD. We selected three samples with average pore diameters, $D_{P}$, of $11.6 \mathrm{~nm}$ (product name: Q-10), $15.0 \mathrm{~nm}(\mathrm{Q}-15)$, and $50.0 \mathrm{~nm}$ (Q-50) to examine the effects of $D_{P}$ on the melting point and latent heat of the PCM contained within the pores. The porous $\mathrm{SiO}_{2}$ grains had narrow pore-size distributions and a porosity of $0.67 \pm 0.015$. These porous $\mathrm{SiO}_{2}$ grains were used in our previous study, and their pore-size distributions and TEM images are shown in Ref. [33].

Table 1 Specifications of porous $\mathrm{SiO}_{2}$ grains used as support material in this study [33]

\begin{tabular}{llll}
\hline Material & Q10 & Q15 & Q50 \\
\hline Average pore diameter [nm] & 11.6 & 16.2 & 50.0 \\
Surface area $\left[\mathrm{m}^{2} \mathrm{~g}^{-1}\right]$ & 317 & 259 & 73.0 \\
True density $\left[\mathrm{kg} \mathrm{m}^{-3}\right]$ & 1.9 & 2.2 & 2.1 \\
Porosity [-] & 0.66 & 0.69 & 0.68 \\
Grain size $[\mathrm{mm}]$ & $1.7-4.0$ & & \\
\hline
\end{tabular}




\section{2 Impregnation experiments}

The $\mathrm{PCM} / \mathrm{SiO}_{2}$ composites were prepared by vacuum impregnation [27]. First, the solid PCM and the porous $\mathrm{SiO}_{2}$ were placed in an electric furnace equipped with a vacuum pump to evacuate the furnace air. Second, the furnace was maintained at room temperature during the evacuation of air from the porous $\mathrm{SiO}_{2}$ grains. Third, the furnace was heated to $383 \mathrm{~K}$ under vacuum. These conditions were maintained until the PCM melted. Finally, the vacuum pump was turned off to allow air to re-enter the furnace. The porous $\mathrm{SiO}_{2}$ filled with PCM was separated from the liquid PCM by a stainless steel mesh, and the liquid PCM captured on the outer surface of the samples (not absorbed by the pores) was removed. Finally, PCM attached around the porous $\mathrm{SiO}_{2}$ grains was mechanically ablated by using polishing paper.

\section{3 Characterization techniques}

The phase-change behaviours of the composites prepared by the impregnation treatments were measured by differential scanning calorimetry (DSC, METTLER TOLEDO DSC823). The data were collected at a heating rate of $0.5 \mathrm{~K} \mathrm{~min}^{-1}$ up to 313 K. The measurements were performed using open aluminium crucibles under nitrogen atmosphere. 


\section{Results and discussion}

\section{1 Thermophysical properties}

Fig. 1 shows the DSC curves of the three investigated octadecane/SiO${ }_{2}$

composites using porous $\mathrm{SiO}_{2}$ with $D_{P}$ values of $11.6 \mathrm{~nm}, 15.0 \mathrm{~nm}$, and $50.0 \mathrm{~nm}$. The

melting point, latent heat, and impregnation ratio, $\eta$, of these three samples are also

summarized in Fig. 1. The impregnation ratio $\eta$ can be expressed by Eq. (1).

$$
\eta=\frac{W_{\text {PCM }}}{V_{P} \cdot W_{\text {Porous }} \cdot \rho_{\text {PCM }}}
$$

Here, $W_{P C M}$ is the weight of the PCM in the composite, $V_{P}$ is the average specific

volume of a pore, $W_{\text {porous }}$ is the weight of the porous material, and $\rho_{P C M}$ is the density of solid PCM. The impregnation ratio $\eta$ of the composites was calculated to be $0.95-1.02$; therefore, almost all of the pores were filled with PCM.

The endothermic fusion peak shifted significantly toward lower temperatures with decreasing $D_{P}$. Interestingly, the melting point decreased to $296 \mathrm{~K}$ in the case of the $\mathrm{PCM} / \mathrm{SiO}_{2}$ composite with $D_{P}=11.6 \mathrm{~nm}$. The change in melting point is attributed to strain in the molecular structure of the PCM inside the pores [32].

Fig. 2 shows the comparison between the experimentally determined and ideal 
latent-heat values of the three PCCs. The ideal value was calculated according to Eq. (2)

under the assumption that the latent heat of the PCM inside the pores was identical to that of bulk PCM.

$$
L_{\text {Ideal }}=L_{\text {bulk }}=\frac{W_{P C M}}{W_{P C M}+W_{\text {Porous }}} L
$$

Here, $L_{\text {Ideal, }} L_{\text {bulk, }} W_{P C M}, W_{\text {Porous }}$, and $L$ represent the ideal latent heat of the PCM in the pores, latent heat of bulk PCM, weight of the PCM in the pores, weight of porous material, and specific latent heat of the PCM, respectively. Clearly, the composites with smaller $D_{P}$ have smaller experimental values of latent heat, even though the impregnation ratio of each sample is almost identical. In addition, the experimental values are remarkably smaller than the ideal values; this is particularly pronounced in the case of PCCs with small $D_{P}$.

The decrease in latent heat can be explained by the existence of " $\mathrm{a}$ nonfreezing layer,” which acts physically as part of the pore wall [34]. As shown in Table 1, the porous materials with smaller $D_{P}$ have larger surface areas because the porosity of all the materials is similar. Therefore, an increase in surface area leads to an 
increase in the fraction of the nonfreezing liquid layer and, as a consequence, the composites with smaller $D_{P}$ have smaller $L$.

\section{3 Analysis of $T_{m}$ of PCCs with different pore sizes}

Based on the experimental data, we attempted to analyse the melting points of the PCCs at different $D_{P}$ values. This analysis method was the same as that used in our previous study on the thermophysical properties of mannitol in mesopores [33].

According to the Gibbs-Thomson equation, the change in melting point depends on the effective pore radius, $r_{e f}$, which is the difference between the pore radius, $r$, and the thickness, $\beta$, of the nonfreezing layer [31, 34].

$r-\beta=r_{e f}$

The Gibbs-Thomson equation is expressed by Eq. (4) [35] as

$$
\Delta T=T_{m, \text { bulk }}-T_{m, \text { pore }}=\frac{2\left(\gamma_{w s}-\gamma_{w l}\right) v T_{m, \text { bulk }}}{L_{m}} \cdot \frac{1}{r_{e f}}
$$

Here, $T_{m, b u l k}$ is the melting temperature of bulk PCM, $T_{m, \text { pore }}$ is the melting temperature of the PCM in the pores, $\gamma_{w s}$ is the wall-solid excess free energy, $\gamma_{w l}$ is the wall-liquid 
excess free energy, $v$ is the molar volume of liquid PCM, and $L_{m}$ is the molar latent heat of PCM. Eq. (4) can be rewritten in the form of Eq. (5) because the interaction between the liquid PCM and the porous material is constant.

$$
r_{e f}=\frac{K_{G T}}{\Delta T}
$$

Eq. (5) can be further rewritten as

$$
T_{m, \text { pore }}=\frac{K_{G T}}{r_{e f}}+T_{m, b u l k}
$$

where $K_{\mathrm{GT}}$ is the Gibbs-Thomson constant [35].

To calculate the effective pore radius $r_{e f}$ of each sample, the nonfreezing liquid layer with thickness $\beta$ needs to be investigated. The difference between the latent heat

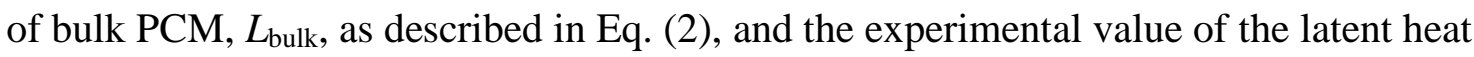
can be determined using $\beta$. According to Lai et al. [36], the latent heat of a material inside a pore, $L_{\text {pore }}$, can be related to the excluded volume of the nonfreezing liquid layer surrounding the solid core. $L_{\text {pore }}$ is expressed by Eq. (7) as 


$$
L_{\text {pore }}=L_{\text {bulk }} \cdot\left(1-\frac{\delta V}{V}\right)
$$

Here, $\delta V$ is the volume of the nonfreezing liquid layer and $V$ is the total volume of a pore. For a spherical particle, $\delta V$ is expressed by Eq. (8) as

$$
\delta V=\frac{4}{3} \pi \cdot\left[r^{3}-(r-\beta)^{3}\right]
$$

Similarly, for a cylindrical pore, $\delta V$ is expressed by Eq. (9) as

$$
\delta V=\pi h \cdot\left[r^{2}-(r-\beta)^{2}\right]
$$

Here, $h$ is the height of the cylinder. Thus, $L_{p o r e}$ can be written as follows:

Spherical pore:

$$
L_{\text {pore }}=L_{b u l k} \cdot\left(1-\frac{\beta}{r}\right)^{3}
$$

Cylindrical pore: 


$$
L_{\text {pore }}=L_{\text {bulk }} \cdot\left(1-\frac{\beta}{r}\right)^{2}
$$

Thus, $L_{\text {pore }}$ was first theoretically estimated using Eqs. (6)-(11), and then $\left(L_{\text {pore }} / L_{0}\right)^{1 / 3}$ and $\left(L_{\text {pore }} / L_{0}\right)^{1 / 2}$ were plotted versus the inverse pore radius $r^{-1}$ for estimating $\beta$. Fig. 3 shows the plots of $\left(L_{p o r e} / L_{0}\right)^{1 / 2}$ and $\left(L_{p o r e} / L_{0}\right)^{1 / 3}$ for cylindrical and spherical pores, respectively, versus $r^{-1}$ and the corresponding least squares fittings to estimate $\beta$. For octadecane, the values of $\beta$ for spherical and cylindrical pores were calculated to be 1.13 and $1.62 \mathrm{~nm}$, respectively.

Fig. 4 shows the relationship between melting point of the PCM inside the pores and $r_{e f}^{-1}$ and the corresponding least squares fittings for the cylindrical and spherical pores. Notably, the melting point of PCM inside the pores linearly decreased with increasing $r_{e f}{ }^{-1}$. According to Eq. (6) and Fig. 4 and assuming that the pore configurations were spherical and cylindrical, the coefficients for the melting-point change of octadecane were found to be 33.0 and 30.0, respectively.

Fig. 5(a) shows the relationship between the ratio of the latent heat of the PCM material inside a pore, $L_{\text {pore }}$, to the latent heat of bulk PCM, $L_{b u l k}$, and the pore radius, $r$. Fig. 5(b) shows the relationship between the melting point of PCM inside a pore, $T_{m \text {,pore, }}$ 
and pore radius, $r$. $L_{p o r e} / L_{b u l k}$ in the case of spherical and cylindrical pores is expressed by Eqs. 12 and 13, respectively, which are based respectively on Eqs. 10 and 11.

Spherical pore:

$\frac{L_{\text {pore }}}{L_{\text {bulk }}}=\left(1-\frac{1.13}{r}\right)^{3}$

Cylindrical pore:

$$
\frac{L_{\text {pore }}}{L_{\text {bulk }}}=\left(1-\frac{1.62}{r}\right)^{2}
$$

The $T_{m, p o r e}$ of octadecane is expressed as a function of $r$ by Eqs. (12) and (13), based on Eq. (6).

Spherical pore:

$$
T_{m, \text { pore }}=-\frac{33.0}{r-1.13}+303
$$

Cylindrical pore:

$$
T_{m, \text { pore }}=-\frac{30.0}{r-1.62}+303
$$


Both the latent heat and the melting point of PCM inside the pores changed remarkably below the pore radius of approximately $20 \mathrm{~nm}$. In particular, the melting point drastically decreased on reducing the pore radius below $20 \mathrm{~nm}$. These results indicate that porous materials with pore radii above $20 \mathrm{~nm}$ (diameters above $40 \mathrm{~nm}$ ) should be used for octadecane-based PCCs.

\section{2 Cyclic tests}

Fig. 6 shows the change in the latent heat of fusion and solidification of octadecane/ $\mathrm{SiO}_{2}$ with a $D_{P}$ of $50 \mathrm{~nm}$ [Fig. 6(a)] and that with a $D_{P}$ of $11.6 \mathrm{~nm}$ [Fig. 6(b)] in cyclic tests of heating and cooling. The latent heat of both composites was constant up to the fifth cycle, resulting from the effect of capillary and surface-tension forces on the porous structure. All composites showed no leakage during melting. 


\section{Conclusion}

This paper describes the development of PCCs without leakage during melting and the analysis of the melting point and latent heat as a function of the pore size of mesoporous $\mathrm{SiO}_{2}$. PCCs of octadecane/porous $\mathrm{SiO}_{2}$ were prepared by vacuum impregnation, and their thermophysical properties, such as melting point and latent heat, were measured by DSC. The following results were obtained:

(1) The impregnation ratios of the PCCs were above 0.95; therefore, almost all pores were completely filled with the octadecane PCM.

(2) The melting points of the PCCs decreased with decreasing average pore diameter. The melting points were derived as a function of average pore diameter from the Gibbs-Thomson equation, taking into account the existence of a nonfreezing layer on the surface of the pore wall.

(3) Both the latent heat and the melting point of octadecane used as a PCM in mesoporous $\mathrm{SiO}_{2}$ decreased significantly below a pore radius of approximately $20 \mathrm{~nm}$. Therefore, porous materials with diameters above $40 \mathrm{~nm}$ should be used for octadecane-based PCCs.

(4) Octadecane/mesoporous $\mathrm{SiO}_{2}$ composites retained the full amount of PCM, even after cyclic heating and cooling. 
The results of the present work will contribute to the development of shape-stabilized PCCs for building applications as the suitable pore-size range of porous materials has been clarified.

\section{Acknowledgements}

This research was partially supported by the Japan Science and Technology (JST) agency, Strategic International Collaborative Research Program (SICORP). 


\section{References}

[1] DOE. 2007 Buildings Energy Data Book. Office of Energy Efficiency and Renewable Energy, US Department of Energy; 2007.

[2] N. Zhu, Z. Ma, S. Wang, Dynamic characteristics and energy performance of buildings using phase change materials: a review, Energ. Convers. Manage. 50 (2009) 3169-3181.

[3] F. Chen, M. Wolcott, Polyethylene/paraffin binary composites for phase change material energy storage in building: A morphology, thermal properties, and paraffin leakage study, Sol. Energ. Mater. Sol. Cell. 137 (2015) 79-85.

[4] G. Li, B. Zhang, X. Li, Y. Zhou, Q. Sun, Q. Yun, The preparation, characterization and modification of a new phase change material: $\mathrm{CaCl} 2 \cdot 6 \mathrm{H} 2 \mathrm{O}-\mathrm{MgCl} 2 \cdot 6 \mathrm{H} 2 \mathrm{O}$ eutectic hydrate salt, Sol. Energ. Mater. Sol. Cell. 126 (2014) 51-55.

[5] V.V. Tyagi, D. Buddhi, Thermal cycle testing of calcium chloride hexahydrate as a possible PCM for latent heat storage, Sol. Energ. Mater. Sol. Cell. 92 (2008) 891-899. [6] A.A. Aydin, A. Aydin, High-chain fatty acid esters of 1-hexadecanol for low temperature thermal energy storage with phase change materials, Sol. Energ. Mater. Sol. Cell. 96 (2012) 93-100.

[7] A. Sari, A. Karaipekli, Preparation, thermal properties and thermal reliability of palmitic acid/expanded graphite composite as form-stable PCM for thermal energy storage, Sol. Energ. Mater. Sol. Cell. 93 (2009) 571-576.

[8] A. Solé, H. Neumann, S. Niedermaier, I. Martorell, P. Schossig, L.F. Cabeza, Stability of sugar alcohols as PCM for thermal energy storage, Sol. Energ. Mater. Sol. Cell. 126 (2014) 125-134.

[9] M.M. Farid, A.M. Khudhair, S.A.K. Razack, S. Al-Hallaj, A review on phase change energy storage: materials and applications, Energ. Convers. Manage. 45 (2004) 1597-1615.

[10] A.M. Khudhair, M.M. Farid, A review on energy conservation in building applications with thermal storage by latent heat using phase change materials, Energ. Convers. Manage. 45 (2004) 263-275.

[11] L.F. Cabeza, C. Castellon, M. Nogues, M. Medrano, R. Leppers, O. Zubillaga, Use of microencapsulated PCM in concrete walls for energy savings, Energ. Build. 39 (2007) 113-119.

[12] V.V. Tyagi, D. Buddhi, PCM thermal storage in buildings: a state of art, Renew. Sustain. Energ. Rev. 11 (2007) 1146-1166.

[13] A. Sharma, V. Tyagi, C. Chen, D. Buddhi, Review on thermal energy storage with 
phase change materials and applications, Renew. Sustain. Energ. Rev. 13 (2009) 318-345.

[14] L. Cabeza, A. Castell, C. Barreneche, A. De Gracia, A. Fernández, Materials used as PCM in thermal energy storage in buildings: a review, Renew. Sustain. Energ. Rev. 15 (2011) 1675-1695.

[15] F. Kuznik, D. David, K. Johannes, J.-J. Roux, A review on phase change materials integrated in building walls, Renew. Sustain. Energ. Rev. 15 (2011) 379-391.

[16] L.F. Cabeza, C. Barreneche, I. Martorell, L. Miró, S. Sari-Bey, M. Fois, H.O. Paksoy, N. Sahan, R. Weber, M. Constantinescu, Unconventional experimental technologies available for phase change materials (PCM) characterization. Part 1. Thermophysical properties, Renew. Sustain. Energ. Rev. 43 (2015) 1399-1414. [17] A.I. Fernández, A. Solé, J. Giró-Paloma, M. Martínez, M. Hadjieva, A. Boudenne, M. Constantinescu, E.M. Anghel, M. Malikova, I. Krupa, Unconventional experimental technologies used for phase change materials (PCM) characterization: part 2-morphological and structural characterization, physico-chemical stability and mechanical properties, Renew. Sustain. Energ. Rev. 43 (2015) 1415-1426. [18] A. Biçer, A. Sari, New kinds of energy-storing building composite PCMs for thermal energy storage, Energ. Convers. Manage. 69 (2013) 148-156.

[19] A. Karaipekli, A. Sari, Preparation, thermal properties and thermal reliability of eutectic mixtures of fatty acids/expanded vermiculite as novel form-stable composites for energy storage, J. Ind. Eng. Chem.16 (2010) 767-773.

[20] A. Sari, A. Karaipekli, C. Alkan, Preparation, characterization and thermal properties of lauric acid/expanded perlite as novel form-stable composite phase change material, Chem. Eng. J. 155 (2009) 899-904.

[21] S. Karaman, A. Karaipekli, A. Sari, A. Bicer, Polyethylene glycol (PEG)/diatomite composite as a novel form-stable phase change material for thermal energy storage, Sol. Energ. Mater. Sol. Cell. 95 (2011) 1647-1653.

[22] Z. Sun, Y. Zhang, S. Zheng, Y. Park, R.L. Frost, Preparation and thermal energy storage properties of paraffin/calcined diatomite composites as form-stable phase change materials, Thermochim. Acta 558 (2013) 16-21.

[23] B. Xu, Z. Li, Paraffin/diatomite composite phase change material incorporated cement-based composite for thermal energy storage, Appl. Energ. 105 (2013) 229-237. [24] C. Alkan, A. Biçer, C. Bilgin, Latent heat energy storage characteristics of building composites of bentonite clay and pumice sand with different organic PCMs, Int. J.

Energ. Res. 38 (2014) 1478-1491.

[25] A. Sari, Fabrication and thermal characterization of kaolin-based composite phase 
change materials for latent heat storage in buildings, Energ. Build. 96 (2015) 193-200. [26] A.M. Goitandia, G. Beobide, E. Aranzabe, A. Aranzabe, Development of content-stable phase change composites by infiltration into inorganic porous supports, Sol. Energ. Mater. Sol. Cell. 134 (2015) 318-328.

[27] T. Nomura, N. Okinaka, T. Akiyama, Impregnation of porous material with phase change material for thermal energy storage, Mater. Chem. Phys. 115 (2009) 846-850. [28] K. Ishikiriyama, A. Sakamoto, M. Todoki, T. Tayama, K. Tanaka, T. Kobayashi, Pore size distribution measurements of polymer hydrogel membranes for artificial kidneys using differential scanning calorimetry, Thermochim. Acta, 267 (1995) 169-180.

[29] K. Ishikiriyama, M. Todoki, Pore size distribution measurements of silica gels by means of differential scanning calorimetry II. Thermoporosimetry, J. Colloid Interface Sci. 171 (1995) 103-111.

[30] K. Ishikiriyama, M. Todoki, Evaluation of water in silica pores using differential scanning calorimetry, Thermochim. Acta, 256 (1995) 213-226.

[31] K. Ishikiriyama, M. Todoki, K. Motomura, Pore size distribution (PSD) measurements of silica gels by means of differential scanning calorimetry I. Optimization for determination of PSD, J. Colloid Interface Sci. 171 (1995) 92-102. [32] Japan Patent Kokai 2007-132580 (2005. 11. 9).

[33] A. Sagara, T. Nomura, M. Tsubota, N. Okinaka, T. Akiyama, Improvement in thermal endurance of D-mannitol as phase-change material by impregnation into nanosized pores, Mater. Chem. Phys. 146 (2014) 253-260.

[34] R. Schmidt, E.W. Hansen, M. Stoecker, D. Akporiaye, O.H. Ellestad, Pore size determination of MCM-51 mesoporous materials by means of 1H NMR spectroscopy, N2 adsorption, and HREM. A Preliminary Study, J. Am. Chem. Soc. 117 (1995) 4049-4056.

[35] A. Schreiber, I. Ketelsen, G.H. Findenegg, Melting and freezing of water in ordered mesoporous silica materials, Phys. Chem. Chem. Phys. 3 (2001) 1185-1195.

[36] S. Lai, J. Guo, V. Petrova, G. Ramanath, L. Allen, Size-dependent melting properties of small tin particles: nanocalorimetric measurements, Phys. Rev. Lett. 77 (1996) 99. 


\section{Caption list}

Fig. 1 DSC curves of PCCs of octadecane/SiO 2 with different $D_{P}$, with their melting points and latent heats.

Fig. 2 Comparison between experimental and ideal latent-heat values of three studied PCCs.

Fig. 3 Plot of $\left(L_{\text {pore }} / L_{b u l k}\right)^{1 / 2}$ for cylindrical and $\left(L_{p o r e} / L_{b u l k}\right)^{1 / 3}$ spherical pores versus $r^{-1}$ and corresponding least-squares fittings to determine $\beta$.

$\mathrm{F}$

Fig. 4 Relationship between $T_{m \text {,pore }}$ and $r_{e f}$ and corresponding least-squares fitting in case of a cylindrical and a spherical pore.

Fig. 5 a) Relationship between $L_{\text {pore }} / L_{\text {bulk }}$ and $r$. b) relationship between $\quad T_{m \text {,pore }}$ and $r$.

Fig. 6 Change of the latent heat of PCC in cyclic heating and cooling between 243 and $313 \mathrm{~K}$. 
Heating rate: $0.5 \mathrm{~K} \mathrm{~min}^{-1}$, Atmosphere: $\mathrm{N}_{2}$, Sample pan: Open Al

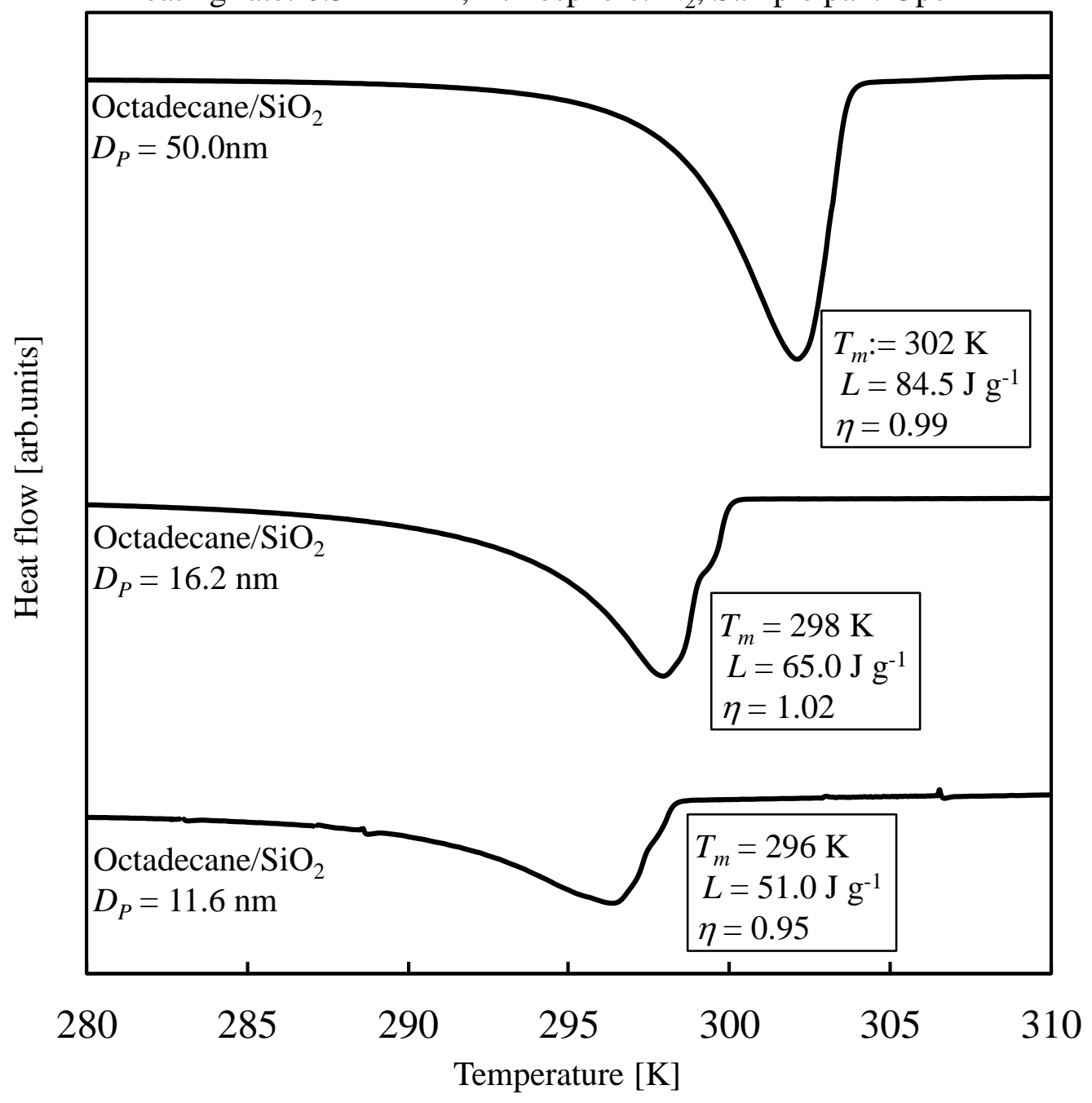

Fig. 1 




Fig. 2 


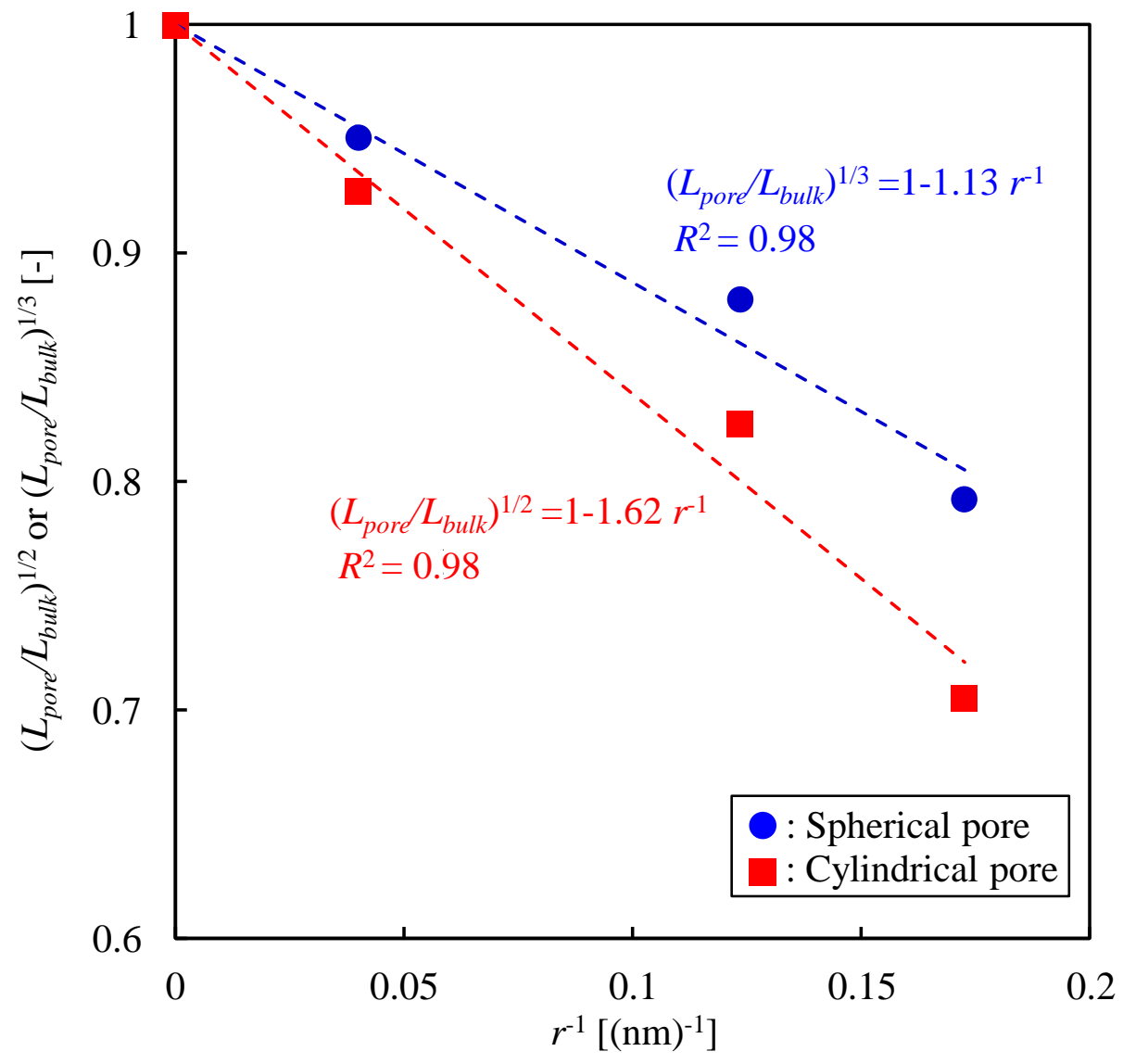

Fig. 3 




Fig. 4 

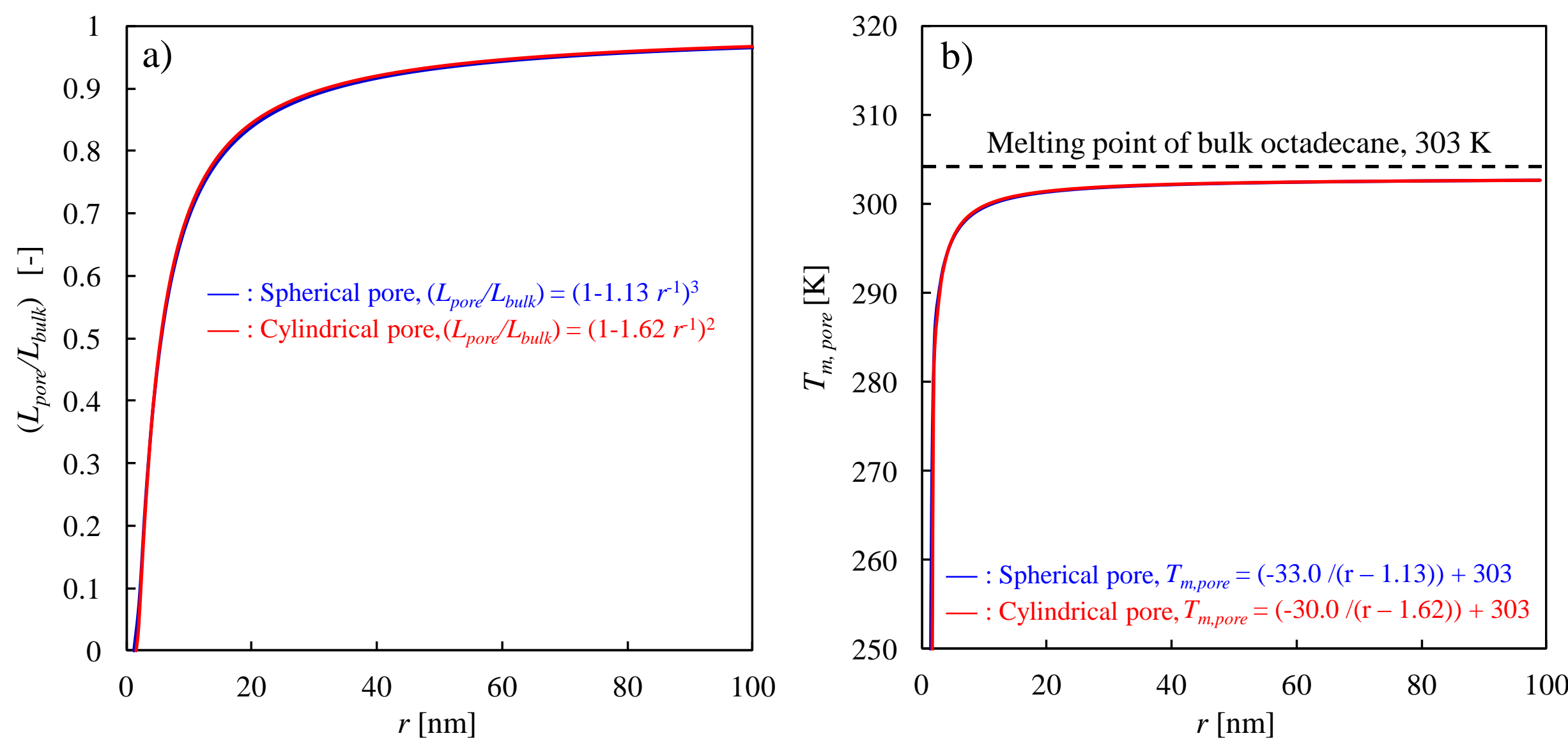

Fig. 5 

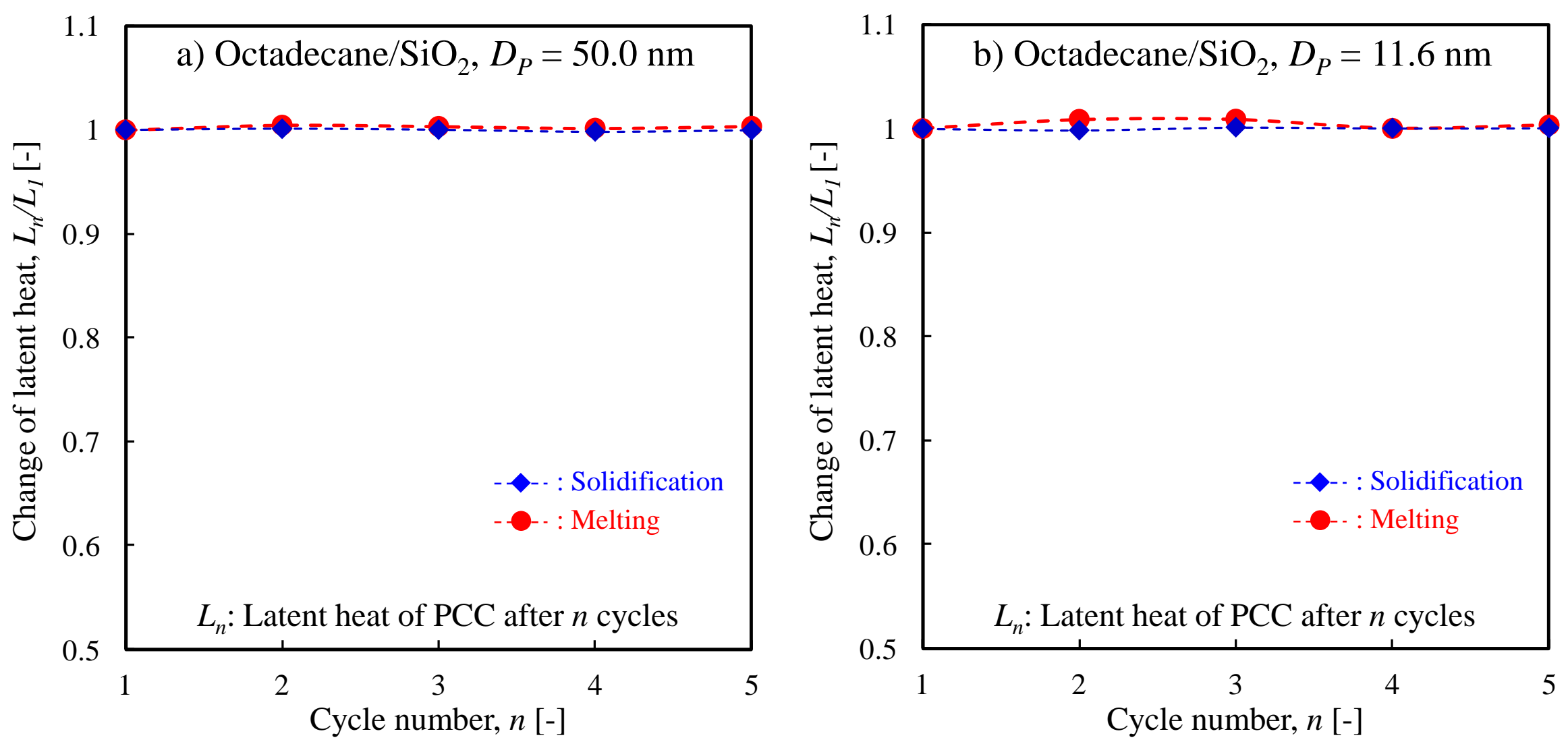

Fig. 6 